\title{
Topographic analysis of the mandibular symphysis in a normal occlusion population using cone-beam computed tomography
}

\author{
JI-EUN LEE ${ }^{1 *}$, YOON-JIN LEE ${ }^{1^{*}}$, SEONG-HO JIN $^{1}$, YOONJI KIM ${ }^{2}$, YOON-AH KOOK $^{2}$, \\ YOUNGKYUNG KO ${ }^{1}$ and JUN-BEOM PARK ${ }^{1}$ \\ Departments of ${ }^{1}$ Periodontics and ${ }^{2}$ Orthodontics, College of Medicine, \\ The Catholic University of Korea, Seoul 06591, Republic of Korea
}

Received December 27, 2014; Accepted September 1, 2015

DOI: $10.3892 /$ etm.2015.2842

\begin{abstract}
At present, the relationship between the morphological characteristics of the sympheseal region and occlusion has not been well documented. The aim of the present study was to investigate the following, using cone-beam computed tomography (CBCT): Interforaminal distance, the anterior loop, labial bone thickness at the tooth apex, cortical bone thickness, and the basal bone height from the apex of the tooth to the base of the mandible. Three-dimensional CBCT was performed on 20 normal occlusion subjects ( 9 males and 11 females; mean age $=21.9 \pm 3.0$ years); the mean interforaminal distance was $53.1 \pm 3.6 \mathrm{~mm}$, with $85 \%$ of the participants demonstrating a mental foramen located below the second premolars on both sides. The mean anterior loop was $1.9 \pm 0.8 \mathrm{~mm}$, the mean horizontal distance value was $4.5 \pm 1.3 \mathrm{~mm}$, and the mean cortical bone thickness value was $2.3 \pm 0.5 \mathrm{~mm}$. An increasing tendency for cortical bone thickness was seen from the central incisor to the second premolar. The mean vertical distance value was $20.3 \pm 3.1 \mathrm{~mm}$. Decreasing tendency of vertical distance was seen from the central incisor to the second premolar. Furthermore, the width (mental foramina of both sides and their anterior loops), height (teeth apices and the inferior border of the mandible), depth (cortical bone thickness of the symphysis), and safety margins for vital anatomical structures (anterior loop, tooth apex, and inferior border of mandible) should be taken into account prior to symphyseal block-bone harvesting. The results of the present study suggested that a pre-operative evaluation with CBCT may be useful for diagnosis and treatment planning, and for minimizing complications during block-bone graft.
\end{abstract}

Correspondence to: Professor Jun-Beom Park, Department of Periodontics, College of Medicine, The Catholic University of Korea, 222 Banpo-daero, Seocho-gu, Seoul 06591, Republic of Korea

E-mail: jbassoonis@yahoo.co.kr

*Contributed equally

Key words: anatomy, chin, cone-beam computed tomography, mandible

\section{Introduction}

Autogenous bone is considered the gold standard in bone grafting (1), and autogenous bone can be obtained from various donor sites, both intraoral and extraoral $(2,3)$. Previous studies have demonstrated that there are various advantages to harvesting intramembranous bone grafts from intraoral sites, as compared with extraorally harvested endochondral bone grafts (4-7), including: Reduced reabsorption, enhanced revascularization (8), and improved incorporation at the donor site (4). As compared with other intraoral sites such as the tuberosity, zygoma, palate, and the coronoid process, the symphyseal region can provide a greater quantity of bone (9). Other advantages of symphyseal grafts include: Diminished postoperative morbidity; reduced or eliminated hospitalization, which, in turn, decreases cost; minimal postoperative discomfort; no alteration in ambulation; and the avoidance of a cutaneous scar (9). However, there are various complications associated with symphyseal bone grafts, including: Intraoperative bleeding, wound dehiscence, mental nerve injury, pulp canal obliteration, and a loss of pulp sensitivity in the anterior lower teeth $(10,11)$.

During pre-operative evaluations for the diagnosis and treatment planning of symphyseal block-bone grafts, an understanding of the anatomical aspects of the safety zone is required in order to minimize complications during surgery. In spite of the necessity for data associated with the symphyseal safety zone, little research has been conducted to quantify the available symphyseal region. Furthermore, the relationship between the morphological characteristics of the sympheseal region and occlusion has not been well documented. Therefore, the aim of the present study was to assess the safety zone when harvesting symphyseal block bone, using cone-beam computed tomography (CBCT).

\section{Materials and methods}

Participants. The data of 20 subjects ( 9 males and 11 females; mean age, $21.9 \pm 3.0$ years) with normal occlusion were obtained from the Department of Orthodontics, The Catholic University of Korea (Seoul, Korea). The 20 subjects and the inclusion criteria were consistent with that of our previous study (12). Briefly, the criteria were: i) Periodontally healthy dentition; ii) normal occlusion; and iii) no previous orthodontic treatment. 
Normal occlusion was defined as i) Angle Class I occlusion; ii) fully developed permanent dentition with a normal overbite and 1-3 mm overjet; iii) no missing or decayed teeth; iv) no prosthetic crowns; v) crowding $<3 \mathrm{~mm}$ and spacing $<1 \mathrm{~mm}$; and vi) no facial asymmetry with crossbite. The present study was approved by the Institutional Review Board of The Catholic University of Korea. A total of 10 teeth, from the left-lower secondary premolars to the right-lower secondary premolars, from all 20 subjects were included for measurements.

Image processing. Three-dimensional CBCT data were obtained using a VEGA (Asahi Roentgen Ind. Co., Ltd., Kyoto, Japan) with a 200x179 mm field of view, $80 \mathrm{kVp}$, and $50 \mathrm{~mA}$, and 0.39 voxel resolution. $\mathrm{CBCT}$ data were exported into the Invivo Dental 5 program (Anatomage, San Jose, CA, USA) from iCAT (Imaging Sciences, Hatfield, PA, USA) software in the DICOM format.

Measurements. To assess the various factors associated with the safety zone when obtaining a symphyseal block-bone graft, the following measurements were obtained from 10 teeth of the 20 subjects, respectively (Fig. 1A and B): i) Interforaminal distance: The locations of the right and left mental foramen were investigated, along with the distance between the two most-mesial points of the mental foramina and the labial cortex of the mandible (Fig. 1A). ii) Anterior loop: The narrowest position of the mandibular canal-incisive canal complex was marked as the anterior border of the anterior loop, and the distance between the most mesial point of the mental foramina and the anterior border of the anterior loop was measured. iii) Thickness of the labial bone: On each cross-sectional image (Fig. 1B) the distance between the tooth apex and the labial surface of the mandible was measured in the best direction for optimal teeth condition, as stated above. iv) Cortical bone thickness: The thickness of the labial cortex bone of the mandible was measured (Fig. 1B). v) Mandible bone height: The height of the mandible from the apex of the tooth to the inferior border of the mandible, was measured (Fig. 1B).

To generate the best resection direction for all 10 teeth, the coronal, sagittal, and axial planes were adjusted to the perpendicular section of each tooth. The axial plane of each tooth consisted of the cusp tip and the apex. The interforaminal distance was measured from all 20 participants, and the horizontal distance, cortical bone thickness, and vertical distance of 200 teeth (10 teeth from each of the 20 subjects) were measured. Image measurements were performed by an independent examiner.

Statistical analysis. The statistical significance of differences in interforaminal distance, horizontal distance, cortical bone thickness, and vertical distance were analyzed between teeth, left- and right-side measurements, and, males and females using SPSS software (version 12.0; SPSS Inc., Chicago, IL, USA). $\mathrm{P}<0.05$ was considered to indicate a statistically significant difference.

\section{Results}

Vertical distance, horizontal distance, interforaminal distance and anterior loop. Measured as described, the mean interforam-
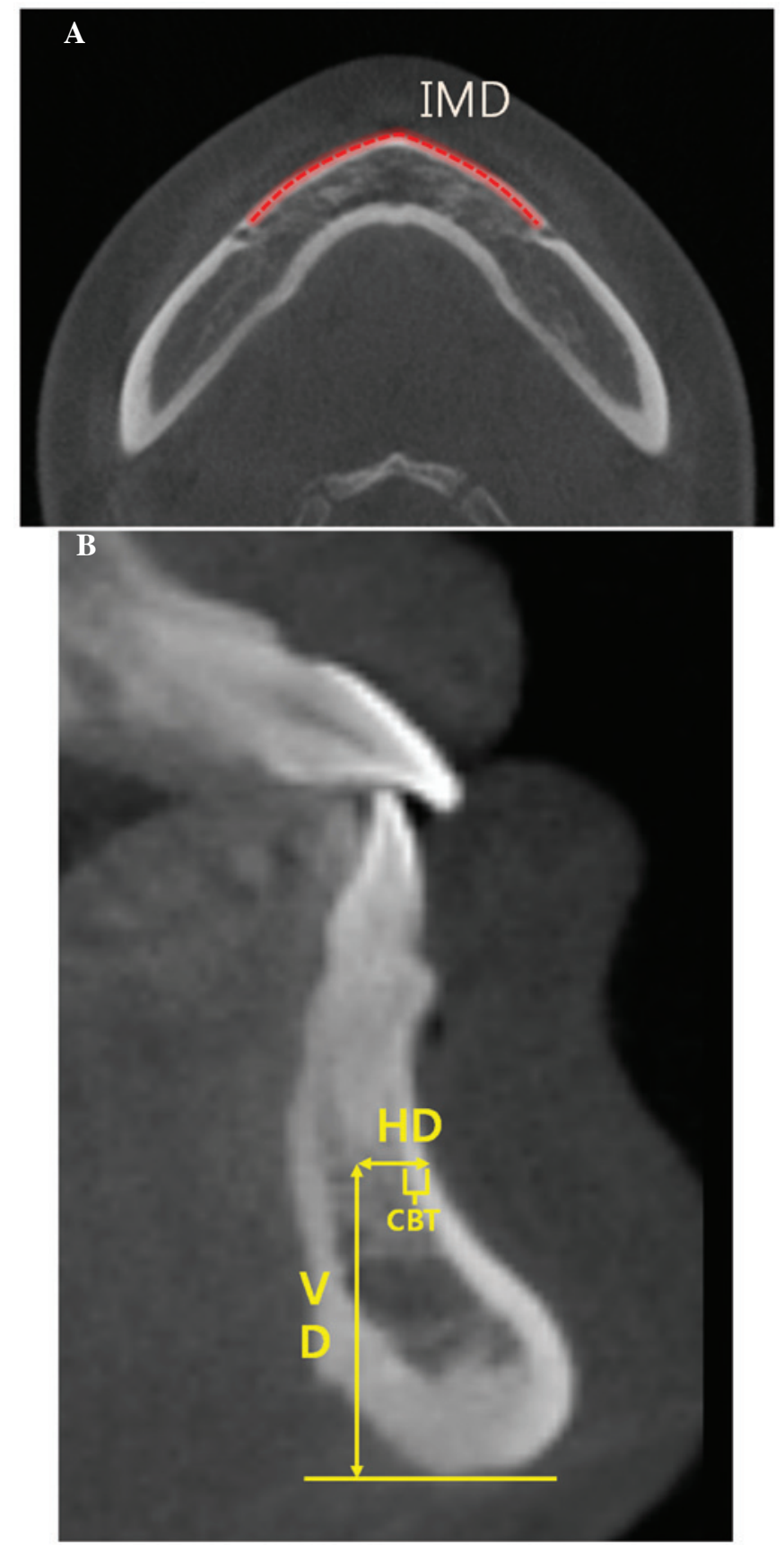

Figure 1. Measurements made on cone-beam computed tomography images. (A) Interforaminal distance (IMD): Distance between the two most-mesial points of the mental foramina, along the labial cortex. (B) Horizontal distance (HD), distance between the apex of the tooth and the labial surface of the mandible; cortical bone thickness (CBT), the thickness of the labial cortex bone; vertical distance (VD), the distance from the apex of the tooth to the inferior border of the mandible.

inal distance was $53.1 \pm 3.6 \mathrm{~mm}$ and the mean anterior loop was $1.9 \pm 0.8 \mathrm{~mm}$ (Table I), whereas the mean thickness of the labial bone was $4.5 \pm 1.3 \mathrm{~mm}$ (Table I). The horizontal distance values for the central incisor, lateral incisor, canine, first premolar, and second premolar were $3.7 \pm 1.1,3.8 \pm 0.8,4.3 \pm 1.0,4.7 \pm 1.0$, and $5.9 \pm 1.2 \mathrm{~mm}$, respectively (Table II and Fig. 2A).

Cortical bone thickness. The mean cortical bone thickness value was $2.3 \pm 0.5 \mathrm{~mm}$ (Table I); whereas the values for the central incisor, lateral incisor, canine, first premolar, and 
Table I. Vertical distance, horizontal distance, cortical bone thickness, interformaminal distance and anterior loop ( $\mathrm{mm}$ ).

\begin{tabular}{lrrrrr}
\hline Parameter & Mean & Median & Maximum & Minimum & Standard deviation \\
\hline Vertical distance & 20.3 & 20.2 & 46.8 & 12.0 & 3.1 \\
Horizontal distance & 4.5 & 4.4 & 9.3 & 1.8 & 1.3 \\
Cortical bone thickness & 2.3 & 2.2 & 4.0 & 1.1 & 0.5 \\
Interforaminal distance & 53.1 & 53.3 & 59.3 & 46.8 & 3.6 \\
Anterior loop & 1.9 & 1.9 & 3.3 & 0.0 & 0.8 \\
\hline
\end{tabular}

Table II. Vertical distance, horizontal distance, and cortical bone thickness (mm) of various teeth.

\begin{tabular}{|c|c|c|c|c|c|}
\hline Tooth parameters & Mean & Median & Maximum & Minimum & Standard deviation \\
\hline \multicolumn{6}{|l|}{ Central incisor } \\
\hline Vertical distance & 22.1 & 22.0 & 26.1 & 17.2 & 3.1 \\
\hline Horizontal distance & $3.7^{\mathrm{a}, \mathrm{b}}$ & 3.5 & 7.5 & 1.8 & 1.1 \\
\hline Cortical bone thickness & $1.8^{\mathrm{a}}$ & 1.7 & 2.7 & 1.2 & 0.4 \\
\hline Tooth dimension & 4.9 & 4.9 & 7.1 & 3.9 & $0.6^{\mathrm{a}, \mathrm{b}, \mathrm{d}}$ \\
\hline \multicolumn{6}{|l|}{ Lateral incisor } \\
\hline Vertical distance & 20.8 & 21.0 & 23.9 & 17.7 & 1.7 \\
\hline Horizontal distance & $3.8^{\mathrm{a}, \mathrm{b}}$ & 3.7 & 5.6 & 2.0 & 0.8 \\
\hline Cortical bone thickness & 2.0 & 2.0 & 2.8 & 1.1 & 0.4 \\
\hline Tooth dimension & 5.4 & 5.4 & 6.9 & 4.5 & $0.6^{\mathrm{a}-\mathrm{c}}$ \\
\hline \multicolumn{6}{|l|}{ Canine } \\
\hline Vertical distance & 20.3 & 19.9 & 46.8 & 14.9 & 4.7 \\
\hline Horizontal distance & $4.3^{\mathrm{c}, \mathrm{d}}$ & 4.3 & 6.3 & 2.7 & 1.0 \\
\hline Cortical bone thickness & 2.3 & 2.3 & 3.1 & 1.5 & 0.3 \\
\hline Tooth dimension & 6.8 & 6.8 & 9.2 & 4.9 & $0.9^{\mathrm{c}, \mathrm{d}}$ \\
\hline \multicolumn{6}{|l|}{ First premolar } \\
\hline Vertical distance & 19.8 & 20.2 & 25.7 & 14.9 & $2.4^{\mathrm{c}, \mathrm{d}}$ \\
\hline Horizontal distance & $4.7^{\mathrm{c}, \mathrm{d}}$ & 4.7 & 6.3 & 1.8 & 1.0 \\
\hline Cortical bone thickness & 2.5 & 2.4 & 3.7 & 1.5 & 0.5 \\
\hline Tooth dimension & 6.3 & 6.3 & 8.1 & 4.9 & 0.7 \\
\hline \multicolumn{6}{|l|}{ Second premolar } \\
\hline Vertical distance & $18.5^{\mathrm{a}-\mathrm{d}}$ & 19.1 & 24.4 & 12.0 & 2.7 \\
\hline Horizontal distance & $5.9^{\mathrm{a}-\mathrm{d}}$ & 6.0 & 9.3 & 3.3 & 1.2 \\
\hline Cortical bone thickness & $2.9^{\mathrm{c}, \mathrm{d}}$ & 2.9 & 4.0 & 2.0 & 0.4 \\
\hline Tooth dimension & 6.3 & 6.2 & 7.9 & 3.0 & $1.0^{\mathrm{c}, \mathrm{d}}$ \\
\hline
\end{tabular}

${ }^{a} \mathrm{P}<0.05$ vs. canine; ${ }^{\mathrm{b}} \mathrm{P}<0.05$ vs. first premolar; ${ }^{\mathrm{c}} \mathrm{P}<0.05$ vs. central incisor; ${ }^{\mathrm{d}} \mathrm{P}<0.05$ vs. lateral incisor.

second premolar were $1.8 \pm 0.4,2.0 \pm 0.4,2.3 \pm 0.3,2.5 \pm 0.5$, and $2.9 \pm 0.4 \mathrm{~mm}$, respectively (Table II and Fig. 2B). Cortical bone thickness increased from the central incisor to the second premolar, and the mean height of the basal bone was $20.3 \pm 3.1 \mathrm{~mm}$ (Table I). The values for the central incisor, lateral incisor, canine, first premolar, and second premolar were $22.1 \pm 3.1,20.8 \pm 1.7,20.3 \pm 4.7,19.8 \pm 2.4$, and $18.5 \pm 2.7 \mathrm{~mm}$, respectively (Table II and Fig. 2C). Basal bone height decreased towards the second premolar.

Topological classification and gender differences. No significant differences were determined between the horizontal distance, cortical bone thickness, and vertical distance measurements on the left- and right-hand sides; with the exception of the cortical bone thickness values at the second premolar (right, $3.0 \pm 0.4 \mathrm{~mm}$; left, $2.7 \pm 0.4 \mathrm{~mm} ; \mathrm{P}=0.049$ ) and the anterior loop (right, 1.7 \pm 0.9 ; left, 2.1 \pm 0.7 ; $\mathrm{P}<0.001$ ) (Table III and IV, and Figs. 3A-C). No significant differences between male and female subjects were determined between the labial bone thickness, cortical bone thickness, and basal bone height measurements (Table $\mathrm{V}$ and Figs. 4A-C). However, the interforaminal distance and the anterior loop were longer in males, as compared with females (Table IV and Fig. 4D; $\mathrm{P}<0.05$ ). These results suggest that there may be more available space for sympheseal block-bone grafts in males, as compared with in females.

\section{Discussion}

Width, height, and depth values are required for the safe harvesting of symphyseal block bone, without invading vital 
$\mathbf{A}$

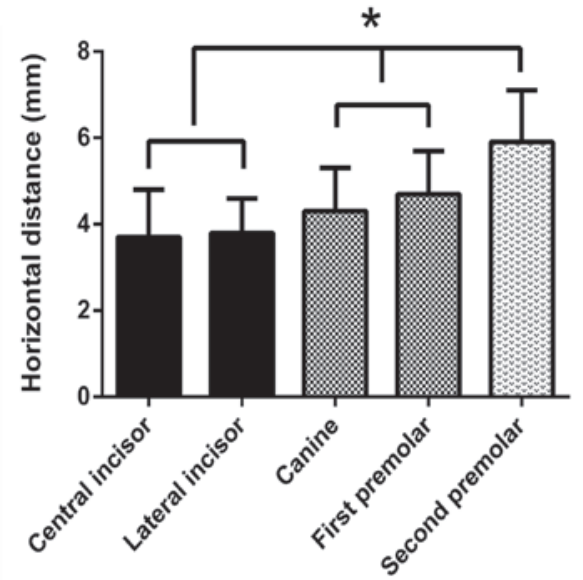

B

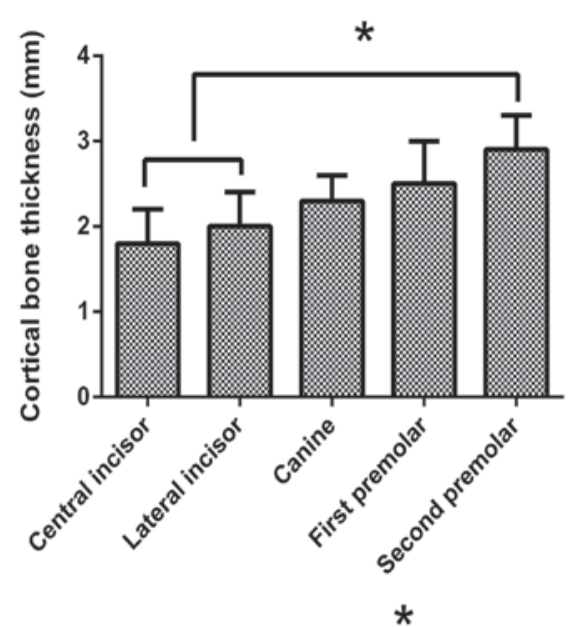

C

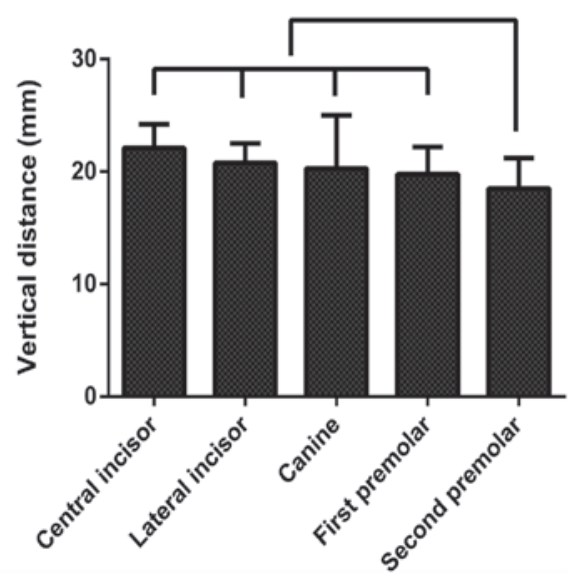

Figure 2. Results of each measurement. (A) Horizontal distance of each tooth. Significant differences were noted among three groups (central and lateral incisors; canine and first premolars; second premolar; " $\mathrm{P}<0.05$ ). (B) Cortical bone thickness of each tooth. Cortical bone thickness increased from the central incisor to the second premolar, and a significant increase was noted in the second premolar, as compared with the central and lateral incisors ( $\left.{ }^{*} \mathrm{P}<0.05\right)$. (C) Vertical distance of each tooth. A decreasing tendency of vertical distance was detected, and the second premolar was significantly different, as compared with the other teeth $\left({ }^{*} \mathrm{P}<0.05\right)$. Data are presented as the mean \pm standard deviation.

anatomical structures. The present study used CBCT to provide values for the safe harvesting of bone from the symphysis area.

It is necessary to measure the interforaminal distance when investigating the width of block-bone harvesting, in order to avoid injury to the surrounding tissue (13). A previous
A

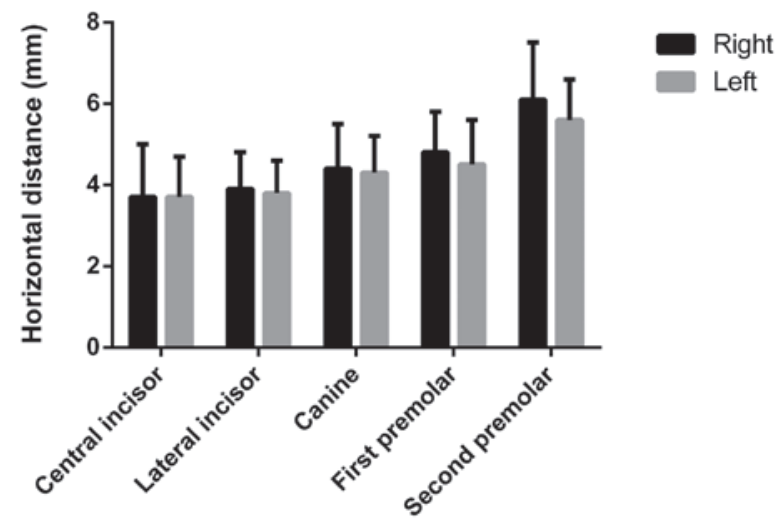

B

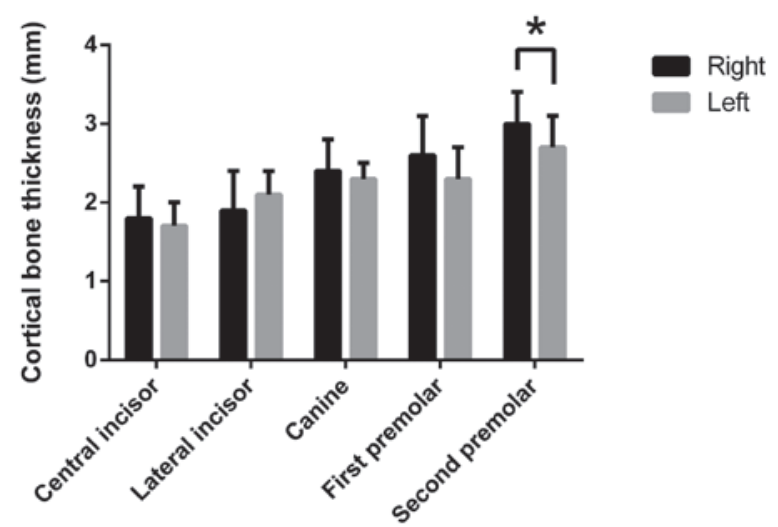

C

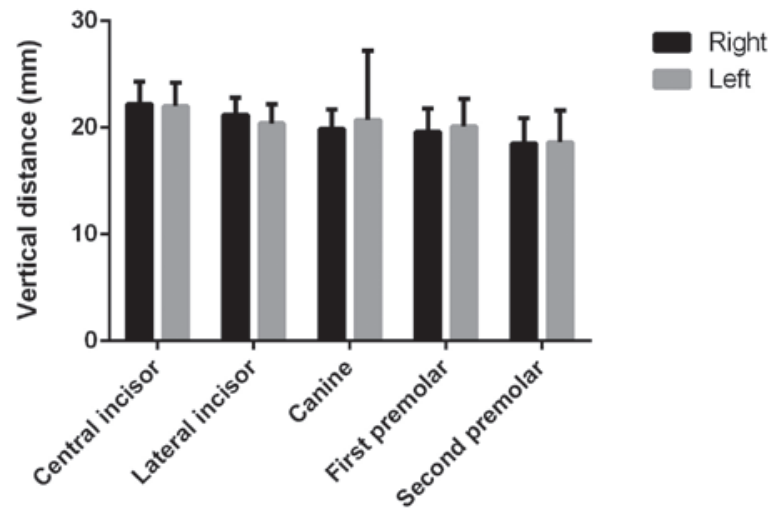

Figure 3. Horizontal distance, cortical bone thickness, and vertical distance, compared by topology. (A) No significant differences in horizontal distance were determined between the right- and left-hand sides. (B) A significant difference in cortical bone thickness was determined in the second premolar (right, $3.0 \pm 0.4 \mathrm{~mm}$; left $2.7 \pm 0.4 \mathrm{~mm}$; ${ }^{*} \mathrm{P}<0.05$ ) between the right- and left-hand sides. (C) No significant differences in vertical distance were determined between the right- and left-hand sides. Data are presented as the mean \pm standard deviation

study demonstrated that the mean interforaminal distance was $49.5 \mathrm{~mm}$, from 42 cadaver samples (14); whereas another study, which analyzed 22 Caucasian skulls, demonstrated a mean interforaminal distance of $55.2 \mathrm{~mm}$ (15). In the present study, the mean interforaminal distance was $53.1 \pm 3.6 \mathrm{~mm}$, as measured using a three-dimensional analysis program.

As the extension of the inferior alveolar nerve beyond the mental foramen (16), the anterior loop is readily identifiable in most patients; and as it contains the entire neurovascular bundle, anterior loop injuries may result in sensory disturbances (17). In a previous study, the anterior loop was detected at a frequency 
Table III. Topological classification of the vertical distance, horizontal distance and cortial bone thickness of various teeth.

\begin{tabular}{|c|c|c|c|c|}
\hline Tooth and topology & $\begin{array}{l}\text { Vertical distance } \\
(\mathrm{mm})\end{array}$ & $\begin{array}{l}\text { Horizontal distance } \\
\qquad(\mathrm{mm})\end{array}$ & $\begin{array}{l}\text { Cortical bone thickness } \\
\qquad(\mathrm{mm})\end{array}$ & $\begin{array}{l}\text { Tooth dimension } \\
(\mathrm{mm})\end{array}$ \\
\hline \multicolumn{5}{|l|}{ Central incisor } \\
\hline Right & $22.2 \pm 2.1$ & $3.7 \pm 1.3$ & $1.8 \pm 0.4$ & $5.0 \pm 0.7$ \\
\hline Left & $22.0 \pm 2.2$ & $3.7 \pm 1.0$ & $1.7 \pm 0.3$ & $4.9 \pm 0.5$ \\
\hline P-value & 0.779 & 0.602 & 0.445 & 0.801 \\
\hline \multicolumn{5}{|l|}{ Lateral incisor } \\
\hline Right & $21.2 \pm 1.6$ & $3.9 \pm 0.9$ & $1.9 \pm 0.5$ & $5.4 \pm 0.5$ \\
\hline Left & $20.4 \pm 1.8$ & $3.8 \pm 0.8$ & $2.1 \pm 0.3$ & $5.5 \pm 0.6$ \\
\hline P-value & 0.135 & 0.834 & 0.221 & 0.527 \\
\hline \multicolumn{5}{|l|}{ Canine } \\
\hline Right & $19.9 \pm 1.8$ & $4.4 \pm 1.1$ & $2.4 \pm 0.4$ & $6.8 \pm 0.9$ \\
\hline Left & $20.7 \pm 6.5$ & $4.3 \pm 0.9$ & $2.3 \pm 0.2$ & $6.8 \pm 0.9$ \\
\hline P-value & 0.718 & 0.968 & 0.529 & 0.963 \\
\hline \multicolumn{5}{|l|}{ First premolar } \\
\hline Right & $19.6 \pm 2.2$ & $4.8 \pm 1.0$ & $2.6 \pm 0.5$ & $6.2 \pm 0.7$ \\
\hline Left & $20.1 \pm 2.6$ & $4.5 \pm 1.1$ & $2.3 \pm 0.4$ & $6.4 \pm 0.8$ \\
\hline $\mathrm{P}$-value & 0.495 & 0.300 & 0.090 & 0.541 \\
\hline \multicolumn{5}{|l|}{ Second premolar } \\
\hline Right & $18.5 \pm 2.4$ & $6.1 \pm 1.4$ & $3.0 \pm 0.4$ & $6.3 \pm 1.2$ \\
\hline Left & $18.6 \pm 3.0$ & $5.6 \pm 1.0$ & $2.7 \pm 0.4$ & $6.3 \pm 0.7$ \\
\hline $\mathrm{P}$-value & 1.000 & 0.201 & 0.049 & 0.895 \\
\hline
\end{tabular}

A

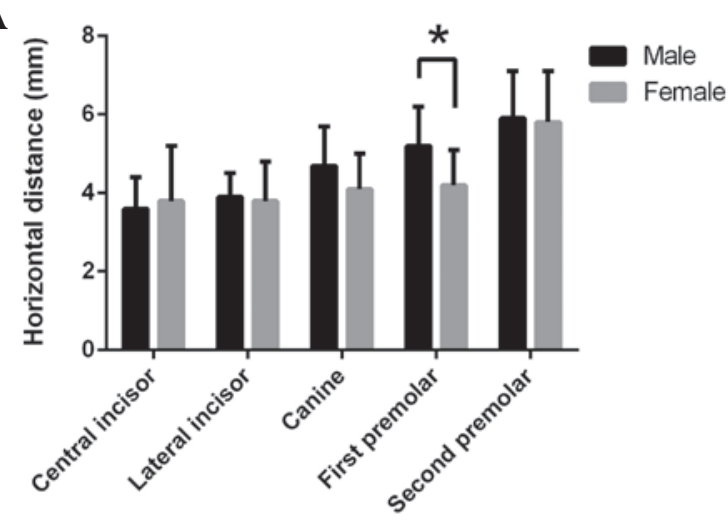

C

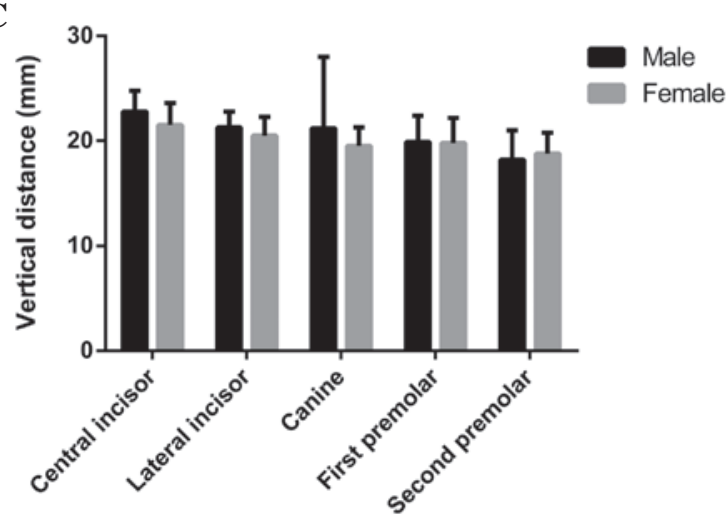

B

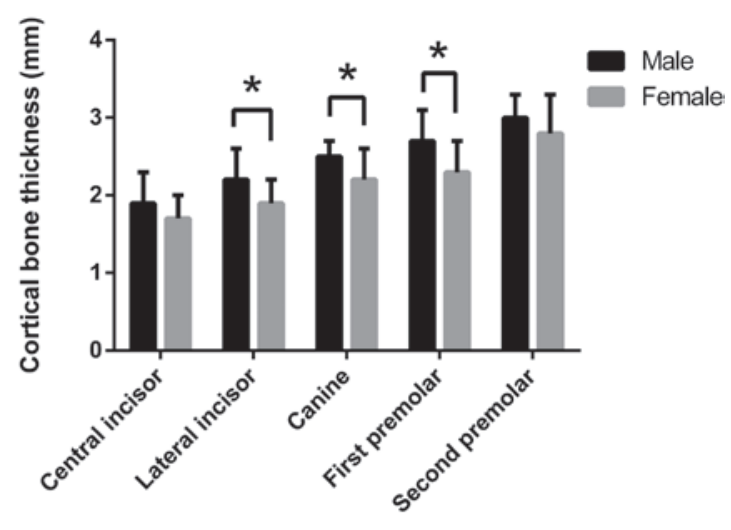

D

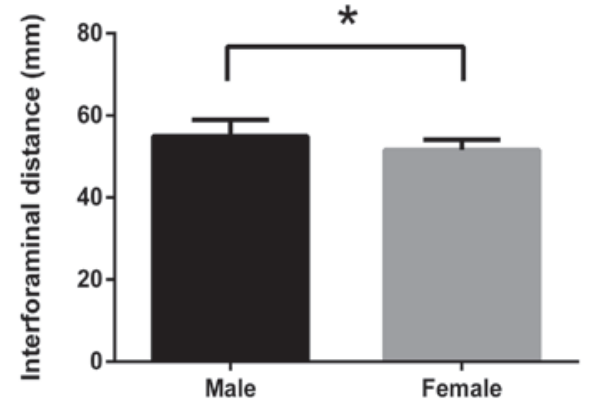

Figure 4. Comparison of each measurement (horizontal distance, cortical bone thickness, and vertical distance) by gender (male and female). (A) Horizontal distance of teeth from male and female subjects. A significant difference in horizontal distance of the first premolars was detected between males $(5.2 \pm 1.0 \mathrm{~mm})$ and females $(4.2 \pm 0.9 \mathrm{~mm})(\mathrm{P}<0.05)$, only. (B) Cortical bone thickness of teeth from male and female subjects. A significant difference $\left({ }^{*} \mathrm{P}<0.05\right)$ was detected between the male and female cortical bone thickness values of the lateral incisor, canine, and first premolar. (C) Vertical distance of teeth from male and female subjects. No significant differences were demonstrated between male and female subjects. (D) Interforaminal distance of male and female subjects. A significant difference was determined in interforaminal distance between males and female subjects ("P<0.05). Data are presented as the mean \pm standard deviation. 
Table IV. Classification of anterior loop by topology and gender, and interforaminal distance by gender.

\begin{tabular}{|c|c|c|c|c|}
\hline Parameter & Topology & Gender & Value (mm) & P-value \\
\hline \multirow[t]{4}{*}{ Anterior loop } & Right & - & $1.7 \pm 0.9$ & \\
\hline & Left & - & $2.1 \pm 0.7$ & $<0.001$ \\
\hline & - & Male & $2.3 \pm 0.6$ & \\
\hline & - & Female & $1.6 \pm 0.8$ & 0.007 \\
\hline \multirow[t]{2}{*}{ Interforaminal distance } & - & Male & $55.0 \pm 3.9$ & \\
\hline & - & Female & $51.6 \pm 2.5$ & 0.028 \\
\hline
\end{tabular}

Table V. Classification of the vertical distance, horizontal distance and cortial bone thickness of various teeth by gender.

\begin{tabular}{|c|c|c|c|c|}
\hline Tooth and gender & $\begin{array}{l}\text { Vertical distance } \\
\qquad(\mathrm{mm})\end{array}$ & $\begin{array}{l}\text { Horizontal distance } \\
\qquad(\mathrm{mm})\end{array}$ & $\begin{array}{l}\text { Cortical bone thickness } \\
\qquad(\mathrm{mm})\end{array}$ & $\begin{array}{c}\text { Tooth dimension } \\
(\mathrm{mm})\end{array}$ \\
\hline \multicolumn{5}{|l|}{ Central incisor } \\
\hline Male & $22.8 \pm 2.0$ & $3.6 \pm 0.8$ & $1.9 \pm 0.4$ & $5.0 \pm 0.6$ \\
\hline Female & $21.5 \pm 2.1$ & $3.8 \pm 1.4$ & $1.7 \pm 0.3$ & $4.9 \pm 0.6$ \\
\hline P-value & 0.089 & 0.778 & 0.396 & 0.307 \\
\hline \multicolumn{5}{|l|}{ Lateral incisor } \\
\hline Male & $21.3 \pm 1.5$ & $3.9 \pm 0.6$ & $2.2 \pm 0.4$ & $5.6 \pm 0.6$ \\
\hline Female & $20.5 \pm 1.8$ & $3.8 \pm 1.0$ & $1.9 \pm 0.3$ & $5.3 \pm 0.5$ \\
\hline $\mathrm{P}$-value & 0.146 & 0.529 & 0.008 & 0.161 \\
\hline \multicolumn{5}{|l|}{ Canine } \\
\hline Male & $21.2 \pm 6.8$ & $4.7 \pm 1.0$ & $2.5 \pm 0.2$ & $7.3 \pm 0.9$ \\
\hline Female & $19.5 \pm 1.8$ & $4.1 \pm 0.9$ & $2.2 \pm 0.4$ & $6.4 \pm 0.6$ \\
\hline P-value & 0.492 & 0.106 & 0.007 & 0.001 \\
\hline \multicolumn{5}{|l|}{ First premolar } \\
\hline Male & $19.9 \pm 2.5$ & $5.2 \pm 1.0$ & $2.7 \pm 0.4$ & $6.4 \pm 0.9$ \\
\hline Female & $19.8 \pm 2.4$ & $4.2 \pm 0.9$ & $2.3 \pm 0.4$ & $6.3 \pm 0.6$ \\
\hline P-value & 0.861 & 0.001 & 0.020 & 0.625 \\
\hline \multicolumn{5}{|l|}{ Second premolar } \\
\hline Male & $18.2 \pm 2.8$ & $5.9 \pm 1.2$ & $3.0 \pm 0.3$ & $6.7 \pm 0.9$ \\
\hline Female & $18.8 \pm 2.6$ & $5.8 \pm 1.3$ & $2.8 \pm 0.5$ & $6.0 \pm 1.0$ \\
\hline P-value & 0.488 & 0.683 & 0.397 & 0.039 \\
\hline
\end{tabular}

of $31 \%$ using CBCT, with an average size of $1.4 \mathrm{~mm}$ and a maximum of $4.6 \mathrm{~mm}$ (17). Previous studies have suggested that osteotomy should be conducted at least 1 (18), 2 (19), 3 (20), 4 (21), 5 (22), or 6 (23) mm anteriorly apart from the mental foramen. As the mean interforaminal distance in this study was $53.1 \mathrm{~mm}$, the available safe width of the symphyseal block-bone harvesting was $<45.1 \mathrm{~mm}$, which was calculated by subtracting the mean length of the bilateral anterior loops, $10 \mathrm{~mm}$ (22), from the mean interforaminal distance.

To investigate the height of block-bone harvesting, the height from the basal bone to the apex of the tooth was measured. To avoid injuries to the teeth and the mandible, surgeons must be aware of the safety margin. Previous studies have suggested a safety zone of 5-8 $\mathrm{mm}$ from the apex of the tooth to the inferior mandibular border (24-26); therefore, in the present study the average available bone height would be $10.3 \mathrm{~mm}$, as $10 \mathrm{~mm}$ is subtracted from the mean height $(20.3 \mathrm{~mm})$.

Depth cuts may be performed in order to determine the thickness of the cortical plate and to minimize cancellous bone harvesting; however, the avoidance of deep cutting is highly recommended in order to decrease the possibility of postoperative paresthesia (24). In the present study, the mean horizontal distance and cortical bone thickness values were $4.5 \mathrm{~mm}$ and $2.3 \mathrm{~mm}$, respectively. However, as these values increased distally this may suggest more autogenous bone can be harvested from a more-distal region.

In the present study, no significant differences were determined between the left- and right-hand sides; however. some gender differences were noted between male and female subjects. In previous studies, the interforaminal distance, anterior loop, horizontal distance, cortical bone thickness, and vertical distance values were increased in male subjects, as compared with female subjects (27-29). Thus suggesting that increased care should be taken to determine what block-bone depth is required in female patients.

The present study evaluated the interforaminal distance, anterior loop, cortical bone thickness, the depth from the tooth apex to the labial cortical bone and the height between the inferior mandibular border, and the apex of the tooth measurements in normal occlusion subjects, with gender and 
topological differences analyzed. The results of the present study suggest that the following should be taken into account prior to symphyseal block-bone harvesting: Width (mental foramina of both sides and their anterior loops), height (teeth apices and the inferior border of the mandible), depth (cortical bone thickness of the symphysis), and safety margins for vital anatomical structures (anterior loop, tooth apex, and inferior border of mandible). Furthermore, in order to minimize any complications that may occur during a block-bone graft, a pre-operative evaluation with CBCT may be useful for patient diagnosis and treatment planning.

\section{Acknowledgements}

Parts of this paper were presented as a poster at the 23rd Annual Scientific Meeting of the European Association for Osseointegration. The present study was supported by the Basic Science Research Program of the National Research Foundation of Korea (NRF) funded by the Ministry of Science, ICT \& Future Planning (grant no. NRF-2014R1A1A1003106).

\section{References}

1. Rogers GF and Greene AK: Autogenous bone graft: Basic science and clinical implications. J Craniofac Surg 23: 323-327, 2012.

2. Misch CM: Comparison of intraoral donor sites for onlay grafting prior to implant placement. Int J Oral Maxillofac Implants 12: 767-776, 1997.

3. Clavero J and Lundgren S: Ramus or chin grafts for maxillary sinus inlay and local onlay augmentation: Comparison of donor site morbidity and complications. Clin Implant Dent Relat Res 5: 154-160, 2003.

4. Borstlap WA, Heidbuchel KL, Freihofer HP and Kuijpers-Jagtman AM: Early secondary bone grafting of alveolar cleft defects. A comparison between chin and rib grafts J Craniomaxillofac Surg 18: 201-205, 1990.

5. Lin KY, Bartlett SP, Yaremchuk MJ, Fallon M, Grossman RF and Whitaker LA: The effect of rigid fixation on the survival of onlay bone grafts: An experimental study. Plast Reconstr Surg 86: 449-456, 1990

6. Smith JD and Abramson M: Membranous vs endochondrial bone autografts. Arch Otolaryngol 99: 203-205, 1974.

7. Zins JE and Whitaker LA: Membranous versus endochondral bone: Implications for craniofacial reconstruction. Plast Reconstr Surg 72: 778-785, 1983.

8. Kusiak JF, Zins JE and Whitaker LA: The early revascularization of membranous bone. Plast Reconstr Surg 76: 510-516, 1985.

9. Misch CM, Misch CE, Resnik RR and Ismail YH: Reconstruction of maxillary alveolar defects with mandibular symphysis grafts for dental implants: A preliminary procedural report. Int J Oral Maxillofac Implants 7: 360-366, 1992.

10. Nóia CF, Ortega-Lopes R, Olate S, Duque TM, de Moraes M and Mazzonetto R: Prospective clinical assessment of morbidity after chin bone harvest. J Craniofac Surg 22: 2195-2198, 2011.

11. Raghoebar GM, Louwerse C, Kalk WW and Vissink A: Morbidity of chin bone harvesting. Clin Oral Implants Res 12: 503-507, 2001.
12. Jin SH, Park JB, Kim N, Park S, Kim KJ, Kim Y, Kook YA and Ko Y: The thickness of alveolar bone at the maxillary canine and premolar teeth in normal occlusion. J Periodontal Implant Sci 42: $173-178,2012$

13. Al-Ani O, Nambiar P, Ha KO and Ngeow WC: Safe zone for bone harvesting from the interforaminal region of the mandible. Clin Oral Implants Res 24 (Suppl A100): 115-121, 2013.

14. Denissen HW, Kalk W, Veldhuis HA and van Waas MA: Anatomic consideration for preventive implantation. Int J Oral Maxillofac Implants 8: 191-196, 1993.

15. Neiva RF, Gapski R and Wang HL: Morphometric analysis of implant-related anatomy in Caucasian skulls. J Periodontol 75: 1061-1067, 2004.

16. Arzouman MJ, Otis L, Kipnis V and Levine D: Observations of the anterior loop of the inferior alveolar canal. Int J Oral Maxillofac Implants 8: 295-300, 1993.

17. Ritter L, Neugebauer J, Mischkowski RA, Dreiseidler T, Rothamel D, Richter U, Zinser MJ and Zoller JE: Evaluation of the course of the inferior alveolar nerve in the mental foramen by cone beam computed tomography. Int J Oral Maxillofac Implants 27: 1014-1021, 2012.

18. Bavitz JB, Harn SD, Hansen CA and Lang M: An anatomical study of mental neurovascular bundle-implant relationships. Int J Oral Maxillofac Implants 8: 563-567, 1993.

19. Misch C: Root form surgery in the edentulous anterior and posterior mandible: Implant insertion. In: Contemporary Implant Dentistry. Third Edition. St. Louis, MO: Mosby Elsevier 221-226, 2008.

20. Mardinger O, Chaushu G, Arensburg B, Taicher S and Kaffe I: Anterior loop of the mental canal: An anatomical-radiologic study. Implant Dent 9: 120-125, 2000.

21. Kuzmanovic DV, Payne AG, Kieser JA and Dias GJ: Anterior loop of the mental nerve: A morphological and radiographic study. Clin Oral Implants Res 14: 464-471, 2003.

22. Greenstein G and Tarnow D: The mental foramen and nerve: Clinical and anatomical factors related to dental implant placement: A literature review. J Periodontol 77: 1933-1943, 2006.

23. Solar P, Ulm C, Frey G and Matejka M: A classification of the intraosseous paths of the mental nerve. Int J Maxillofac Implants 9: 339-344, 1994.

24. Hunt DR and Jovanovic SA: Autogenous bone harvesting: A chin graft technique for particulate and monocortical bone blocks. Int J Periodontics Restorative Dent 19: 165-173, 1999.

25. Pommer B, Tepper G, Gahleitner A, Zechner W and Watzek G: New safety margins for chin bone harvesting based on the course of the mandibular incisive canal in CT. Clin Oral Implants Res 19: 1312-1316, 2008.

26. Montazem A, Valauri DV, St-Hilaire $H$ and Buchbinder D: The mandibular symphysis as a donor site in maxillofacial bone grafting: A quantitative anatomic study. J Oral Maxillofac Surg 58: 1368-1371, 2000.

27. Garvin HM and Ruff CB: Sexual dimorphism in skeletal browridge and chin morphologies determined using a new quantitative method. Am J Phys Anthropol 147: 661-670, 2012.

28. Wang Q, Ashley DW and Dechow PC: Regional, ontogenetic, and sex-related variations in elastic properties of cortical bone in baboon mandibles. Am J Phys Anthropol 141: 526-549, 2010.

29. Lee KA, Kim MS, Hong JY, Lee JS, Choi SH, Chai JK and Jung UW: Anatomical topography of the mandibular symphysis in the Korean population: A computed tomography analysis. Clin Anat 27: 592-597, 2014. 